Speed and crashes

\section{Reducing injury from speed related road crashes}

\section{Johnston}

\section{Towards the achievement of a population based preventive strategy}

W

hile speed management is a key element in the road safety strategies of many regional and national governments, there is little consensus and much controversy over the specific speed reduction interventions that have been employed. Considerable heat-and relatively little light-has accompanied the public debates.

This paper reviews the evidence for a population based speed reduction strategy, based predominantly on the widespread mismatch between extant speed limits and levels of infrastructure safety. It then explores how jurisdictions have inflamed public opposition to their interventions with flawed public policy decision making and concludes, hopefully, by putting the baby firmly back in the bath.

\section{EVIDENCE FOR SPEED REDUCTION IS IRREFUTABLE}

There can be no doubt that decreasing vehicle travel speeds reduces stopping distances and impact speeds, and thus the incidence of serious casualties and fatalities. While individual studies can be criticised, the weight of evidence, both within and across methodological paradigms, is overwhelming:

(1) Numerous studies, across many countries, have evaluated the injury outcomes of changes in prevailing speed limits, both urban and rural. Almost invariably, fatalities and serious casualties have fallen when speed limits have been lowered and have increased when speed limits have been raised. ${ }^{12}$ On interstate highways in the United States, for example, the limit was reduced in the 1970s, restored to its original level in the late 1980s then further increased, in numerous states, in the mid to late 1990s. Fatalities fell, rose, and then rose again correspondingly. ${ }^{3}$ Such is the consistency of results from these types of study that some writers have posited predictive relationships between shifts in speed distribution and crash injury outcomes.

(2) Case-control studies, of which there are few, show that both the probability of involvement in a casualty crash and the severity of injury when a crash occurs increase exponentially with travel speeds above the speed limit, in both urban and rural environments. ${ }^{5}$ Debate, however, continues as to the precise form of the relationship.

(3) Crash reconstruction research demonstrates the critical role of impact speed in injury severity, revealing (quite low) threshold impact speeds that determine the probability of fatality for particular crash types. $^{7}$

(4) Correlational research of average speeds and crash history on a wide range of typical rural roads in the United Kingdom (with the same speed limit) showed that while road standard influenced crash history, higher average travel speeds resulted in higher crash records across all road standards. ${ }^{8}$

Note that the high incidence of "speeding" reported from police investigations of the causes of serious casualty crashes is not included in the evidence listed above, simply because police investigations are not scientific (in the traditional sense of the term) and are directed at uncovering breaches of traffic law.

This evidence should not surprise us. It is entirely consistent with the laws discovered by Sir Isaac Newton in the 17th century describing the motion of objects.

\section{RE-FOCUS THE PUBLIC DEBATE ON THE OBJECTIVE FIRST, AND THE MEANS SECOND}

Because "energy (is) the necessary and specific cause of injury" the focus in injury reduction is on minimising energy transfer to the human body. The goal should therefore be to decrease travel speeds only on those roads and/or in those traffic environments where there is a mismatch between the prevailing travel speeds and the extant level of protection provided by the vehicle, road, and traffic engineering safety systems.

A road with full access control, with appropriate vertical and horizontal geometric design, with a skid resistant pavement, with separation of opposing traffic flows, and with medians and roadsides guarded to protect errant vehicles from rigid objects can safely sustain "high" travel speeds for vehicle occupants who are protected by seat belts, airbags, and at least "four star" crashworthy vehicle structures. Vulnerable road users such as pedestrians, cyclists, and motorcyclists must be either denied access to such high speed roads or provided with protected, segregated travelling lanes.

Conversely, even for well protected vehicle occupants, undivided two lane roads with relatively poor pavement conditions, narrow or unsealed shoulders, relatively poor geometric design, and with roadsides replete with rigid objects or non-traversable terrain cannot safely sustain high speeds.

Yet many countries have a ubiquitous open road speed limit, with higher limits applied only to the highest standard roads. Moreover, these ubiquitous limits are almost invariably higher than the research would suggest is safe, not only on most of the open road network but in many urban areas with high pedestrian and bicyclist activity and a high frequency of potential vehicle conflict points. We choose generic limits for their convenience in traffic management and make them high because of the dominance of travel time in transport planning. Put simply, we do not have a sufficiently safe vehicle and road infrastructure for the speeds common on much of the network. This is not well understood. Unfortunately, all too frequently, the road safety professional is seen as opposing travel speed per se. We must correct this perception.

\section{NEVERTHELESS, THE CONTROVERSY LIES MOSTLY IN THE HOW}

The simplest means of achieving the goal of matching travel speeds to the level of system safety in particular road/ traffic environments is via the speed limit. Yet governments in most countries are reluctant to reduce speed limits, primarily because accessibility and personal mobility constitute the rationale for transport. The history of human transport is a history of achieving ever shorter journey times-the steam ship replaced the sailing ship, the railway replaced the horse and carriage, and the 
automobile replaced the horse and bicycle. Most road agencies have, as key performance indicators, average journey times in various parts of the networks for which they are responsible. Finally, motoring organisations vehemently oppose proposals to reduce speed limits on the grounds of restrictions to mobility.

Governments prefer, therefore, to seek to manage unsafe speeds by other means, the most common being by enforcement of the speed limits. The most controversial means of enforcement is the speed camera, which is, of course, also the most efficient. ${ }^{10}$

\section{WHY IS THERE CONTROVERSY OVER SPEED ENFORCEMENT?}

Controversy exists because we have failed to convince the community that, in many parts of our road networks, everybody should slow down in the interests of protecting the community at large. Our (implicit) speed management strategy is a population based strategy of prevention. As Rose argues, as a principle in preventive medicine, such a strategy is necessary whenever risk is widely diffused throughout a population. ${ }^{11}$ Unfortunately-for the public's perception of speed enforcement-while this strategy brings large benefits to the community it offers little to, or is actually negative for, each participating individual.

And that is the nub of our problem. As drivers we know that the risk of involvement in a casualty crash on any given trip is extremely small, even when we exceed the speed limit by "moder-

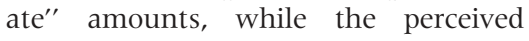
rewards of doing so are high and immediate. Our task of encouraging the driving public to engage in socially valuable behaviour at a perceived personal cost is made even more difficult by the way in which travel speed is portrayed in our society. Cars are designed, built, marketed, and sold with a substantial emphasis on speed and power and travel speed is glorified in television, film, printed media, and through motor sport. ${ }^{12}$

As an aside, the design of the speedometer breaks all the rules that students learn in "Ergonomics 101". The driver most needs to monitor his speed in the lower ranges of modern vehicle capability-from $40 \mathrm{~km} / \mathrm{h}$ through $100 \mathrm{~km} / \mathrm{h}$ yet that range occupies less than one half of the meter. Half the meter is devoted to speeds that are illegal on all but autobahns.

\section{OUR OWN WORST ENEMY}

As if it were not enough that the cultural milieu works counter to reducing travel speeds, we compound the problem by being our own worst enemy. We will not make progress until we confront and resolve these barriers of our own making. Consider the following:

(1) One regularly reads that large proportions of drivers exceed the speed limit much, if not most, of the time. ${ }^{13}$ But the posted speed limit is not the perceived speed limit. Because of concerns over potential legal challenges, travel speeds are only enforced when they exceed the speed limit plus a sanctioned "tolerance". The tolerance is normally of the order of $10 \%$ or 10 $\mathrm{km} / \mathrm{h}$, whichever is the greater. For example, in New Zealand the general urban speed limit of $50 \mathrm{~km} / \mathrm{h}$ is not enforced below $60 \mathrm{~km} / \mathrm{h}$. The tolerance is based on provisions for inaccuracies in vehicle speedometers and in enforcement technology such as radar and speed cameras. The reality is that relatively few drivers speed, that is, few exceed the perceived speed limit. Drivers behave rationally; most comply with the message we convey, albeit indirectly, as to what is regarded as safe. In Victoria, Australia, the enforcement tolerance was very publicly reduced at the same time as the enforcement intensity was increased by a substantial margin. This combination led to a huge public outcry and made speed enforcement a political issue at the next election (but it also led to a substantial reduction in death and serious injury). ${ }^{14} 15$

The fact that the perceived speed limit is well above the posted speed limit is especially troubling when one recognises that traffic regulations generally state that the posted limit is the maximum and require road users to select their actual speed in accord with the prevailing conditions.

(2) Many governments cannot resist the temptation to put revenues derived from increased enforcement, particularly enforcement via speed cameras, into general revenue, though typically after netting off the costs of the increased enforcement. Not surprisingly, the public reaction to the government "pocketing" the large increases in revenue generated by the intense use of speed cameras creates a perception of "revenue raising" and reinforces the prevailing community view that (low level) speeding is not a serious safety issue. Applying the revenue to road system safety improvements would likely change public perception.

(3) Many governments treat automated speed enforcement differently from conventional police officer based enforcement. For example, in New Zealand, a motorist detected speeding by a police officer receives both a fine and demerit points while a motorist detected speeding by a speed camera receives a fine only. This further reinforces the public view that enforcement by speed cameras is primarily designed to raise revenue and not to save lives and injury-because it attracts a "less serious" penalty. The official reasonwhich relates to difficulties in assigning points to a licence when only the owner can be identified by the camera-is irrelevant to public perception.

(4) We structure enforcement practice in an effort to minimise public reaction rather than to maximise the injury reduction outcomes and, in so doing, subvert the underpinning preventive strategy. For example, in the United Kingdom, speed cameras are only placed on sections of road with raised crash experience, with the sites made conspicuous by brightly painting both poles and housings and by using alerting signs. This constitutes an enforcement black spot treatment, exactly analogous to an engineering black spot treatment. Evaluations show such enforcement black spot treatments to be effective in reducing casualty crashes at those high crash locations but with no residual impact on travel speeds generally in the network. ${ }^{16}$ It is a valuable weapon in the road safety armoury but it is not a population based preventive strategy as it does not address system-wide speed behaviour. In Victoria, Australia the speed cameras (which are mobile car based units) are now placed "anywhere at anytime". This is an attempt to get a system-wide reduction in travel speeds, a greater overall level of injury reduction, and a longer term shift in the norms of speed behaviour. It is unquestionably controversial. Widespread implementation is too recent for scientific evaluations to have been completed, though early indications are promising. In Queensland, Australia the government adopted a middle-ofthe-road strategy in which a very large number of sites with raised crash rates have been identified and cameras are rotated around those sites more or less at random. Evaluations have shown this to be an effective method. ${ }^{17}$

\section{CONCLUSIONS}

Achieving a match, within the different road classes/traffic environments, between travel speeds and the differing levels of system safety provided by a combination of vehicle, road, and traffic engineering is a priority objective for road safety professionals. The limits of the modern vehicle to protect against fatal injury in the event of a crash are quite modest - an impact speed around $40 \mathrm{~km} / \mathrm{h}$ for a pedestrian, around $50 \mathrm{~km} / \mathrm{h}$ for the occupant of a vehicle 


\section{GUEST EDITORIAL}

impacted in the side, around $50 \mathrm{~km} / \mathrm{h}$ for an impact with a rigid roadside object, and around $70 \mathrm{~km} / \mathrm{h}$ for a passenger vehicle occupant in a head-on collision with another vehicle. Moreover, and most importantly, few countries have road infrastructure that sustains safe travel at current (perceived) speed limits on more than a minority of their road networks. While raising the (physical) level of road environment safety must be a priority for governments through their road infrastructure agencies, the time frame on which network-wide system safety matches can be achieved is long. In the interim we have no alternative but to reduce travel speeds on those roads where the extant system safety is insufficient. The most effective way of achieving this is to reduce the posted speed limit and to enforce it efficiently via automated techniques. However, this is unsustainable without the support of the community. To win that support, we must first remove all those obstacles that we have created ourselves and secondly we must explain ourselves far better than we have done thus far.
Injury Prevention 2004;10:257-259.

doi: 10.1136/ip.2004.006486

Correspondence to: Professor lan Johnston, Monash University Accident Research Centre (MUARC), Building 70, Monash University, Victoria 3800, Australia; ian.johnston@ general.monash.edu.au

\section{REFERENCES}

1 Anderson G, Nilssen G. Speed management in Sweden. VTI: Linköping, 1997.

2 Insurance Institute for Highway Safety. Specia issue: low priority assigned to highway safety. Status Report 2002;37(10).

3 Farmer CM, Retting RA, Lund AK. Changes in motor vehicle occupant fatalities after repeal of the national maximum speed limit. Accid Anal Prev 1999;31:537-43.

4 Patterson TL, Frith WJ, Povey $\amalg$, et al. The effect of increasing rural interstate speed limits in the United States. Traffic Injury Prevention 2002;3:316-20.

5 Kloeden CN, McLean AJ, Glonek G. Reanalysis of travelling speed and the risk of crash involvement in Adelaide, South Australia. Report CR 207. Canberra: Australian Transport Safety Bureau, 2002

6 Kloeden CN, Ponte G, McLean AJ. Travelling speed and the risk of crash involvement on rural roads. Report CR 204. Canberra: Australian Transport Safety Bureau, 2001.

7 Anderson RWG, McLean AJ, Farmer MJB, et al. Vehicle travel speeds and the incidence of fatal pedestrian crashes. Accid Anal Prev 1997;29:667-74.

8 Taylor MC, Baruya A, Kennedy JV. The relationship between speed and accidents on rural single-carriageway roads. Report TRL511. UK: Transport Research Laboratory, 2002.

9 Robertson LS. Injury epidemiology. London: OUP, 1992:212.

10 Pilkington P. Commentary: speed cameras under attack in the United Kingdom. Inj Prev 2003;9:293-4.

11 Rose G. The strategy of preventive medicine. UK: Oxford University Press, 1992.

12 Ferguson SA, Hardy AP, Williams AF. Content analysis of television advertising for cars and minivans: 1983-1998. Accid Anal Prev 2003;35:825-31.

13 Silcock D, Smith K, Knox D, et al. What limits speed? Factors that affect how fast we drive. London: AA Foundation for Road Safety Research, 2000.

14 Johnston IR. Improving road safety in the longe term - finding the right buttons to push. Keynote address to 2003 Road Safety Research, Policing and Education Conference, 24-26 September, Sydney, Roads and Traffic Authority, NSW, 2003.

15 Delaney A, Diamantopoulou K, Cameron M. MUARC's speed enforcement research: principles learnt and implications for practice. Report No 200. Victoria: Monash University Accident Research Centre, 2003.

16 Gains A, Humble R, Heydecker B, et al. The cost recovery system for speed and red-light cameras - two year pilot evaluation. London, UK: Research paper prepared for Department for Transport (Road Safety Division), 2003.

17 Newstead S, Cameron M. Evaluation of crash effects of the Queensland speed camera program. Proceedings 2003 Road Safety Research, Policing and Education Conference, 24-26 September, Sydney, Roads and Traffic Authority, NSW, CD-ROM, 2003. 